\title{
Karot Operatörü Olarak Çalışan Erkek Bireylerin Üreme Sağlığı Durumları Hakkında Bir Araştırma
}

\author{
A Survey on Reproductive Health Situations of Male Individuals Working as Core Boring Operators
}

\section{Savaş KANBUR ${ }^{1}$, Ali Kemal EYÜBOĞLU ${ }^{2}$}

1. İstanbul Gedik Üniversitesi, Sağlık Bilimleri Fakültesi, İ̧ Sağlığı ve Güvenliği Bölümü, İstanbul, Türkiye

2. Maltepe Üniversitesi, Meslek Yüksekokulu, Iş Sağlığı ve Güvenliği Bölümü, Istanbul, Türkiye

\section{$\ddot{O Z Z E T}$}

Amaç: Madencilik ve yapr sektöründe karot numunesi alma işlemlerinde operatör olarak çalı̧̧anların maruz kaldığı gürültü̈, toz ve sicaklık gibi farklı türden risk etmenlerine bağlı sağlı sorunlarının ortaya çıktığı bilinmektedir. Bu araştırma, Marmara Bölgesi'nde madencilik ve yap sektöründe karot operatörü olarak çalışan evli erkeklerin üreme sağliğl durumlarının tespiti amacıyla yapulmuştır.

Gereçler ve Yöntem: Bilimsel bu araştırmayı yapmak için gerekli etik izin, ilgili kurum tarafindan alınmıştır. Bu çalışmada, Marmara Bölgesi'nde madencilik ve yapı sektöründe karot operatörü olarak çalışan 75 evli erkek çallşan ile farklı sektörlerde ofis ortaminda çalışan 75 evli erkek arastırma örneklemine alınarak elde edilen veriler kategorize edilip ki-kare testi ile test edilmiş ve anlamlılık düzeyi $p<0,05$ olarak alınmıştır.

Bulgular: Karot numunesi alma işlerinde operatör olarak çalışan evli erkeklerin üreme sağllğg ile ilgili olarak, düşük saylsl, ölü doğum ve eşin gebe kalma sürelerinde kontrol grubu ile aralarında istatistiksel olarak anlamlılık gözlenmiștir. Üreme sağllğ ile ilgili göstergelerin BMI, alkol kullanımı, sigara kullanımı ve kronik hastalıklar ile olan anlamlılıkları da istatistiksel olarak incelenmiştir.

Sonuç: Yapılan anketler ve istatistiksel çalışmalar neticesinde çalışma koşulları ve demografik özelliklerine bağlı olarak karot numunesi alma ișlerinde operatör olarak çalıșan erkeklerin üreme sağlığı etkilenimlerinin ofis ortamında çalışan erkeklere göre $(p<0,05)$ düzeyinde anlamlı bulunmuştur.

Anahtar Kelimeler: üreme sağllğgl, karot sektörü, iş sağlı̆̆l ve güvenliği, madencilik sektörü, yapı sektörü

\section{ABSTRACT}

Objective: It is known that in the mining and construction sector, health problems related to various types of risk factors such as noise, dust and temperature exposed to the workers as operators are known in the process of taking core samples. This research was conducted to determine the reproductive health status of married males working as core boring operators in the mining and construction sector in the Marmara Region.

Material and Methods: The ethical permission required to carry out this scientific inquiry has been obtained by the relevant institution. In this study, 75 married male workers working in the mining and construction sector in the Marmara Region and 75 male married men working in the office in different sectors were categorized and tested by chi-square test and the level of significance was $p<0,05$.

\section{İletişim Bilgileri}

Sorumlu Yazar: Ali Kemal EYÜBOĞLU

Yazışma Adresi: Gedik Ünv, Kartal Yerleşke, Cumhuriyet Mh Illkbahar Sk No: 1-3-5 Yakacık 34876 Kartal İstanbul, Türkiye E-posta: savas.kanbur@gedik.edu.tr

Tel: +90 (216) 4524585

Makale Geliş Tarihi: 16.11.2017

Makale Kabul Tarihi: 05.01.2018

DOI: http://dx.doi.org/10.16948/zktipb.354340
Results: Regarding the reproductive health of married males working as operators in core sampling, statistical significance was observed between the control group and the low number, stillbirth and spousal pregnancy durations. Statistical significance of BMI, alcohol use, smoking and chronic diseases were also examined for reproductive health-related indicators.

Conclusion: As a result of the questionnaires and statistical studies, it was found that the reproductive health effects of men working as operators in core sampling were significant $(p<0,05)$ compared to men working in the office environment, depending on working conditions and demographics.

Keywords: reproductive health, drilling core sector, occupational health and safety, mining sector, construction sector

\section{GÍRIŞ}

Zemin, beton, asfalt gibi yapılardan özel aygit yardımıyla (karotiyer) silindirik örnek alma işlemine karot ve bu işlemi yapan çalışana ise karot operatörü denir. Özellikle son yıllarda ülkemizdeki kentsel dönüşüm kapsamındaki binaların depreme fiziksel dayanıklık testlerinin yapılması ve madencilik sektöründe de cevher numunesi almak amacryla ilgili firmalar tarafindan, binaların kolon ve kiriş gibi yapı elemanları ve yeraltı kayaç formlarından, karot operatörleri karotiyer denilen iş makinalarını kullanılarak numuneler almaktadır (1). Karot numunesi alınırken, solunabilir zararlı tozlar ve 85 desibelden fazla gürültü gibi fiziksel risk etmenleri ortaya çıkmaktadır. Ayrıca numune alınan boş yüzeyler operatörler tarafından içeriğinde kuvars ve reçine gibi solunum sistemine zarar veren malzemelerle doldurulmakta ve bu malzemeler de operatörlerin sağlığı için ayrı bir risk unsuru haline gelmektedir (2). Karot işlerinde çalışma ortam koşulları göz önüne alındığında, çalışanlarda en fazla toza ve gürültüye maruziyet vardır. Akciğerlere yapışan silis ve asbest tanecikleri birçok solunum sistemi rahatsızlı̆̆ına sebebiyet vermektedir. Karot işlerindeki risk etmenlerinden bir tanesi titreşimdir. Yüksek voltaj ile çalışan hilti ve matkap benzeri bir iş makinası olan karotiyeri kullanan operatör titreşime bağlı maruziyet yaşamaktadır. Karot operatörleri için bir diğer önemli risk etmeni ise çalışma ortamındaki sıcaklık değişimleridir. Gerek kapalı gerekse açık ortamda olsun, karot işleri her mevsim yapıldığı için bu sektörde çalışanların vücutları s1caklık değişimlerine maruz kalmaktadır. Karot operatörleri çalışma hayatları boyunca birden fazla risk etmenine maruz kaldıkları için bu süreç içerisinde çeşitli vücut sistemlerinde maruziyete bağlı olarak etkilenmeler olmaktadır (3). 
Karot operatörlerinin maruz kaldığı bu tür fiziksel risk etmenleri ayrıca çalışanların psikolojisi üzerinde de olumsuz etkiler yaratarak hem çalışma hayatlarını hem de fizyolojik yaşamlarını olumsuz yönde etkilemektedir (4). Üreme sağlığı da etkilenen bu sistemler içerinde yer almaktadır $(5,6)$.

\section{GEREÇ ve YÖNTEM}

Marmara Bölgesi'nde madencilik ve yap1 sektöründe çalışan ve demografik özellikler bakımindan benzerlik gösteren 75 evli ve erkek karot operatörü ile ofis ortamında çalışan 75 evli ve erkek ofis çalışanı gönüllülük esasına göre belirlenerek bu çalışmaya alınmıştır. Araştırmayı yapmak için gerekli etik izin, ilgili kurum tarafından 21.11.2016 tarihinde alınmıştır. Araştırmaya katılım gösteren her iki gruba da aynı anket formu verilerek gerekli bilgilendirmeler yapıldıktan sonra iş akışını da bozmayacak şekilde her gün gruplar halinde ve gözlem altında yanıtlama tekniği ile çalışanlardan anketleri doldurmaları istenmiştir. Anket formunun içeriği üç kısımdan oluşmaktadır. İlk kısım çalışanların demografik özellikleri, ikinci ve üçüncü kısım ise çalışanların üreme sağlığ durumları ile ilgili sorulardan oluşmaktadır. Çalışanlara yapılan anketler sonucunda elde edilen verilerin analizi SPSS 21.0 paket programı kullanılarak yapılmıştır (7). Gruplar arasındaki anlamlılık ilişkileri kategorik değişkenler için uygulanan ki-kare bağımsızlık testi ile analiz edilerek sınanmıştır. Tüm istatistiksel analizlerde iki yönlü testler kullanılmış olup, anlamlılık düzeyi de $\mathrm{p}<0.05$ olarak alınmıştır.

\section{BULGULAR}

Üreme sağlığ 1 tespiti hakkında yapılan bu bilimsel araştırmaya katılan karot operatörü çalışanlarının demografik özellikleri ile ofis ortamında çalışanların üreme sağlığ göstergelerinin karş1laştırılması Tablo 1., Tablo 2. ve Tablo 3.'de gösterilmiştir. Çalışmaya katılanlardan karot işinde çalışanların yaş dağılımları 37,99 $\pm 9,99$, çalışma süreleri $7,48 \pm 4,6$; kontrol grubunda da yaş dağ1lımları 37,08 $\pm 7,89$, çalışma süreleri de $11,68 \pm 7,43$ olarak saptanmıştır. Üreme sağlığını olumsuz yönde etkileyen sigaranın çalışanlar arasında, karot operatörlerinde \% 61,3, kontrol grubunda da \% 44,0 olduğu görülmüștür. Elde edilen veriler istatistiksel olarak incelendiğinde, "Eşte düşük (Abortus) öyküsü", "Eşte ölü doğum öyküsü” ve "Eşte gebe kalma süresi" parametreleri, kontrol grubundaki erkek çalışanlara göre anlamlı ölçüde farklılık göstermektedir. Anomalili doğum öyküsünün alkol, sigara kullanımı, kronik hastalık öyküsü ve BMI gibi parametrelerden dolayı istatistiksel olarak anlamlilik göstermemesi, karot sanayinde çalışma ortamının, çalışanların üreme sağlığı üzerine olumsuz etki yapabileceği düşünülmektedir. Karot operatörü ve ofis elemanı olan evli ve erkek çalışanların eşlerinin eğitim seviyelerine bakıldığında, aralarında \% 50'den fazla bir fark bulunmakta ve bu veri de karot sektöründeki erkek çalışanların eşlerinin daha çok ev hanımı olduğunu ve üreme sağ Ĭğ$_{1}$ açısından farklı riskler taşıyan ortamlardan yüksek oranda uzak olduğunu göstermektedir.
Tablo 1: Karot sektöründe ve ofis ortamlarında çalışan erkeklerin üreme sağ lığı verileri karşılaştırması.

\begin{tabular}{|c|c|c|c|c|}
\hline $\begin{array}{l}\text { Üreme sağlığı } \\
\text { parametreleri }\end{array}$ & $\begin{array}{c}\text { Karot } \\
\text { Operatörü }\end{array}$ & $\begin{array}{c}\text { Ofis } \\
\text { Çalışanı }\end{array}$ & ki-kare & $p$ \\
\hline $\begin{array}{l}\text { Eşte gebe kalma süresi } \\
<12 \text { ay } \\
>12 \text { ay }\end{array}$ & $\begin{array}{l}69 \\
15\end{array}$ & $\begin{array}{c}69 \\
6\end{array}$ & 4,485 & 0,034 \\
\hline $\begin{array}{l}\text { EMR } \\
\text { Yok } \\
\text { Var }\end{array}$ & $\begin{array}{c}72 \\
3\end{array}$ & $\begin{array}{c}66 \\
9\end{array}$ & 3,261 & 0,071 \\
\hline $\begin{array}{l}\text { Eşte düşük } \\
\text { (Abortus) öyküsü } \\
\text { Yok } \\
\text { Var }\end{array}$ & $\begin{array}{l}53 \\
22\end{array}$ & $\begin{array}{c}66 \\
9\end{array}$ & 6,872 & 0,009 \\
\hline $\begin{array}{l}\text { Eşte erken doğum } \\
\text { öyküsü } \\
\text { Yok } \\
\text { Var }\end{array}$ & $\begin{array}{c}71 \\
4\end{array}$ & $\begin{array}{c}66 \\
9\end{array}$ & 2,106 & 0,147 \\
\hline $\begin{array}{l}\text { Eşte ölü doğum } \\
\text { öyküsü } \\
\text { Yok } \\
\text { Var }\end{array}$ & $\begin{array}{c}71 \\
4\end{array}$ & $\begin{array}{c}75 \\
0\end{array}$ & 4,110 & 0,043 \\
\hline $\begin{array}{l}\text { Eşte doğumsal anomalili } \\
\text { bebek öyküsü } \\
\text { Yok } \\
\text { Var }\end{array}$ & $\begin{array}{c}73 \\
2\end{array}$ & $\begin{array}{c}75 \\
0\end{array}$ & 2,027 & 0,155 \\
\hline
\end{tabular}

Tablo 2: Araştırmaya alınan erkek çalışanların demografik özellikleri $(n=150)$.

\begin{tabular}{|c|c|c|c|c|c|}
\hline \multirow[b]{2}{*}{ Özellik } & & \multicolumn{2}{|c|}{$\begin{array}{c}\text { Karot } \\
\text { Operatörleri }\end{array}$} & \multicolumn{2}{|c|}{$\begin{array}{c}\text { Ofis } \\
\text { çalışanları }\end{array}$} \\
\hline & & $n$ & $\%$ & $\mathbf{n}$ & $\%$ \\
\hline \multirow{4}{*}{ Yaş } & $\leq 25$ & 7 & 9,3 & 1 & 1,3 \\
\hline & $26-34$ & 23 & 30,7 & 29 & 38,7 \\
\hline & $35-45$ & 28 & 37,3 & 36 & 48,0 \\
\hline & $\geq 46$ & 17 & 22,7 & 9 & 12,0 \\
\hline \multirow{4}{*}{ Ağırlık (kg) } & $\leq 59$ & 1 & 1,3 & 1 & 1,3 \\
\hline & $60-79$ & 33 & 44,0 & 26 & 34,7 \\
\hline & $80-89$ & 28 & 37,3 & 26 & 34,7 \\
\hline & $\geq 90$ & 13 & 17,3 & 22 & 29,3 \\
\hline \multirow{4}{*}{ Boy $(\mathrm{cm})$} & $\leq 159$ & - & - & 1 & 1,3 \\
\hline & $160-169$ & 19 & 25,3 & 7 & 9,3 \\
\hline & $170-179$ & 40 & 53,3 & 43 & 57,3 \\
\hline & $\geq 180$ & 16 & 21,3 & 24 & 32,0 \\
\hline \multirow{4}{*}{$\mathrm{BMI} \mathrm{kg} / \mathrm{m}^{2}$} & $\leq 19,9$ & 2 & 2,7 & 1 & 1,3 \\
\hline & $20-24,9$ & 24 & 32,0 & 24 & 32,0 \\
\hline & $25-29,9$ & 32 & 42,7 & 37 & 49,3 \\
\hline & $\geq 30$ & 17 & 22,7 & 13 & 17,3 \\
\hline \multirow{2}{*}{ Sigara kullanımı } & Hayır & 29 & 38,7 & 42 & 56,0 \\
\hline & Evet & 46 & 61,3 & 33 & 44,0 \\
\hline \multirow{2}{*}{ Alkol kullanım } & Hayır & 61 & 81,3 & 37 & 49,3 \\
\hline & Evet & 14 & 18,7 & 38 & 50,7 \\
\hline \multirow{3}{*}{ Eğitim } & $\leq 8 \mathrm{yıl}$ & 58 & 77,3 & 7 & 9,3 \\
\hline & $8-12$ yıl & 12 & 16,0 & 10 & 13,3 \\
\hline & ZYüksekokul & 5 & 6,6 & 46 & 61,3 \\
\hline \multirow{2}{*}{$\begin{array}{l}\text { Kronik Hastalık } \\
\text { Tanısı }\end{array}$} & Yok & 63 & 84,0 & 63 & 84,0 \\
\hline & Var & 12 & 16,0 & 12 & 16,0 \\
\hline
\end{tabular}


Tablo 3: Karot operatörü ve ofis çalışanı olan erkeklerin üreme sağlığı verileri ile bazı demografik özelliklerin karşılaştırması.

\begin{tabular}{|c|c|c|c|c|c|c|c|}
\hline & & \multicolumn{2}{|c|}{ Eşin Gebe Kalma Süresi } & \multicolumn{2}{|c|}{ Eşte Ölü doğum } & \multicolumn{2}{|c|}{ Düşük (Abortus) } \\
\hline & & $<12$ ay & $>12$ ay & Var & Yok & Var & Yok \\
\hline \multirow{4}{*}{$\begin{array}{l}\text { Alkol } \\
\text { Kullanımı }\end{array}$} & Evet & 47 & 5 & 1 & 51 & 8 & 44 \\
\hline & Hayır & 82 & 16 & 3 & 95 & 23 & 75 \\
\hline & Chi-square & \multicolumn{2}{|c|}{1,271} & \multicolumn{2}{|c|}{0,170} & \multicolumn{2}{|c|}{1,354} \\
\hline & $\mathrm{p}$ & \multicolumn{2}{|c|}{0,260} & \multicolumn{2}{|c|}{0,681} & \multicolumn{2}{|c|}{0,245} \\
\hline \multirow{4}{*}{$\begin{array}{l}\text { Sigara } \\
\text { Kullanımı }\end{array}$} & Evet & 69 & 10 & 3 & 76 & 18 & 61 \\
\hline & Hayır & 60 & 11 & 1 & 70 & 13 & 58 \\
\hline & Chi-square & \multicolumn{2}{|c|}{0,250} & \multicolumn{2}{|c|}{0,822} & \multicolumn{2}{|c|}{0,457} \\
\hline & $\mathrm{p}$ & \multicolumn{2}{|c|}{0,617} & \multicolumn{2}{|c|}{0,365} & \multicolumn{2}{|c|}{0,499} \\
\hline \multirow{4}{*}{$\begin{array}{l}\text { Kronik Hastalık } \\
\text { Öyküsü }\end{array}$} & Evet & 20 & 4 & 1 & 23 & 8 & 15 \\
\hline & Hayır & 109 & 17 & 3 & 123 & 22 & 104 \\
\hline & Chi-square & \multicolumn{2}{|c|}{1,276} & \multicolumn{2}{|c|}{0,569} & \multicolumn{2}{|c|}{9,970} \\
\hline & $\mathrm{p}$ & \multicolumn{2}{|c|}{0,937} & \multicolumn{2}{|c|}{0,989} & \multicolumn{2}{|c|}{0,076} \\
\hline \multirow{6}{*}{$\begin{array}{l}\text { BMI } \\
\left(\mathrm{kg} / \mathrm{m}^{2}\right)\end{array}$} & $0-19$ & 3 & 0 & 0 & 3 & 0 & 3 \\
\hline & $20-24,9$ & 42 & 6 & 2 & 46 & 6 & 42 \\
\hline & $25-29,9$ & 59 & 10 & 1 & 68 & 16 & 53 \\
\hline & $>30$ & 25 & 5 & 1 & 29 & 9 & 21 \\
\hline & Chi-square & \multicolumn{2}{|c|}{0,769} & \multicolumn{2}{|c|}{0,944} & \multicolumn{2}{|c|}{4,596} \\
\hline & $\mathrm{p}$ & \multicolumn{2}{|c|}{0,857} & \multicolumn{2}{|c|}{0,815} & \multicolumn{2}{|c|}{0,204} \\
\hline
\end{tabular}

\section{TARTIŞMA}

Gebelik ürünün hem anne hem de babadan gelen üreme hücrelerinden etkilenmesinden dolay1, üreme sağlığı göstergelerinde yer alan tüm parametrelerdeki etkilenmeler iki yönlü olarak gerçekleşmektedir. Marmara Bölgesi'nde madencilik ve yap1 sektöründe hizmet veren kurumlarda karot operatörü olarak çalışan evli ve erkek çalışanlar ile ofis ortamında çalıșan evli ve erkek çalıșanlar arasında yapılan kesitsel bu araştırmada, çalışan erkeklerin eşlerinin hamilelik öncesi, hamilelik süreci ve hamilelik sonrası dönemlerde karşılaștıkları üreme sağlığı problemleri anket yoluyla tespit edilmiştir.

Her iki çalışma ortamında çalışanların iş hayatlarında maruz kaldıkları bazı risk faktörlerinin, nedeni bilinmeyen bazı üreme sağlığ kayıplarına sebep olabileceği düşüncesi ile karot sektörüne ait kitlesel olarak bu bilimsel araștırma yapılmıştır. Yapılan analizler neticesinde karot sektöründe çalışan evli erkek çalışanlardaki üreme sağlıklarına dair bozulmaların, ofis ortamında çalışan evli ve erkek çalışanlara göre anlamlı oranda yüksek olduğu gözlenmiştir. Bu araştırma, karot operatörlerinin çalışma ortam ve koşullarının evli ve erkek çalışanların üreme sağlıklarına olumsuz etkilerinin olabileceğini ve ileriki dönemlerde bu konu hakkında yapılacak daha detaylı bilimsel araştırmalara $1 s ̧ 1 k$ tutabileceğini göstermektedir.

\section{KA YNA KLAR}

1. McIntyre M, Scanlon A. Interpretationand Application of Core Test Data in Strength Evaluation of Existing Concrete Bridge Structures. Can J Civ Eng. 1990;471-80.

2. Bekele A, Yoseph A. Relative chronic effects of different occupational dusts on respiratory indices and health of workers in three Ethiopian factories. Am J Ind Med. 1998;373-80.

3. Momen M, Ananian F, Fahmy I, Mostafa T. Effect of high environmental temperature on semen parameters among fertile men. Fertil Steril. 2010;93(6):1884-6.

4. Gündüz Ş. İs yerinde yaşanan sendromlar. İstanbul: Beta; 2017.

5. Baranski B. Effects of the workplace on fertility and related reproductive outcomes. Environ Health Perspect. 1993;101(2):81-90.

6. $\quad$ Aydın S. Erkek üreme sağlı̆̆g. Van Tip Derg. 2000;7(3).

7. Gümüş A, Dağll S, Yüksel A, Aydin T, Kale U, Botan $E$, vd. Van Organize Sanayi Bölgesi (OSB)'ndeki İsyerlerinin Halk Sağlı̆̆ Açısından Değerlendirilmesi. Van Tip Derg. 2016;23(1). 